\title{
The Long-Term Safety of Adalimumab Treatment in Moderate to Severe Psoriasis
}

\section{A Comprehensive Analysis of All Adalimumab Exposure in All Clinical Trials}

\author{
Craig Leonardi, ${ }^{1}$ Kim Papp, ${ }^{2}$ Bruce Strober, ${ }^{3}$ Kristian Reich, ${ }^{4}$ Akihiko Asahina, ${ }^{5}$ Yihua Gu, ${ }^{6}$ Joseph Beason, ${ }^{6}$ \\ Stephen Rozzo ${ }^{6}$ and Stephen Tyring ${ }^{7}$ \\ 1 Central Dermatology, St. Louis, MO, USA \\ 2 Probity Medical Research, University of Western Ontario, Waterloo, ON, Canada \\ 3 Department of Dermatology, New York University School of Medicine, New York, NY, USA \\ 4 Dermatologikum Hamburg, Hamburg, Germany \\ 5 Sagamihara National Hospital, Sagamihara, Japan \\ 6 Abbott Laboratories, Abbott Park, IL, USA \\ 7 University of Texas Health Science Center, Department of Dermatology, Center for Clinical Studies, Houston, TX, USA
}

\section{Abstract}

\section{Introduction}

Psoriasis is a chronic, immune-mediated, inflammatory skin disease that affects $1-3 \%$ of the general population. ${ }^{[1]}$ Although
Background: A favorable benefit-risk profile has been established for adalimumab, with up to 5 years of treatment in 13 clinical trials in patients with moderate to severe chronic plaque psoriasis.

Objective: The aim of this analysis was to assess the long-term safety of all adalimumab exposure in all psoriasis clinical trials.

Methods: A total of six sets of data were analyzed as follows: (i) all cumulative safety data from all exposure for all adalimumab-treated patients in the 13 clinical trials in moderate to severe psoriasis (All Adalimumab Treatment Population) through April 2007, November 2008, and November 2009, respectively; (ii) longitudinal data for 1403 patients treated with adalimumab $40 \mathrm{mg}$ every other week (eow) dosing (Every Other Week Population) through June 2007 and April 2010; and (iii) data from placebo-controlled periods of clinical trials. Adverse events that occurred up to 70 days after the final dose of adalimumab were analyzed. Results: During placebo-controlled periods, a total of 572 patients had 173.0 patient-years (PYs) of exposure to placebo and 1188 patients had 370.5 PYs of exposure to adalimumab. Adverse event incidence rates, expressed as events per $100 \mathrm{PYs}$ (events/100 PYs), for placebo- and adalimumab-treated patients for serious adverse events were 7.52 and 8.64, and for serious infectious adverse events were 2.89 and 2.43 , respectively.

In the 2007, 2008, and 2009 All Adalimumab Treatment Population there were, respectively, 1819 patients (2424.7 PYs), 2197 patients (4351.9 PYs), and 3010 patients (4844.7 PYs), with serious adverse event incidence rates of $6.51,7.22$, and 8.36 events/100 PYs, and serious infectious adverse event rates of 1.32, 1.38, and 1.65 events/100 PYs.

In the 2007 and 2010 Every Other Week Population $(n=1403)$, there were 1883.5 and 2854.1 total PYs of exposure, respectively, with serious adverse event incidence rates of 6.32 and 6.87 events/100 PYs, and serious infectious adverse event rates of 1.33 and 1.37 events/100 PYs, respectively.

Conclusions: Multiple lines of evidence from a total of six sets of safety data, with treatment for up to 5 years, including results from all adalimumab-treated patients, and a subset of patients treated with $40 \mathrm{mg}$ eow dosing, did not show evidence of cumulative toxicity, and showed adverse event rates that were generally stable or decreased with increased mean per-patient exposure. 
these therapies has led to the development of alternative treatment options. ${ }^{[2]}$ The proinflammatory cytokine, tumor necrosis factor (TNF), is thought to play an integral role in the pathogenesis of psoriasis, and elevated levels of TNF lead to keratinocyte hyperproliferation. ${ }^{[3]}$ Adalimumab is a fully human, monoclonal IgG1 antibody that binds TNF with high specificity and affinity and inhibits TNF activity by blocking interaction with its cognate p55 and p75 cell surface TNF receptors. ${ }^{[4]}$ Adalimumab is approved for the treatment of rheumatoid arthritis, juvenile idiopathic arthritis, psoriatic arthritis, ankylosing spondylitis, Crohn disease, and psoriasis in the US, Canada, Japan, and Europe. Adalimumab has been tested in clinical trials in six indications, including psoriasis, and in a total of more than 19000 patients with over 25000 patientyears (PYs) of exposure. ${ }^{[5]}$ More than 500000 patients with these six immune-mediated inflammatory diseases have been treated with adalimumab worldwide.

Despite the large number of studies performed and patients treated with TNF antagonists during the past 10 years, questions remain about the long-term use of these agents in psoriasis. For example, the role of anti-inflammatory cytokines has often been raised in the context of host defense against serious infections, as well as other adverse events of interest. ${ }^{[6]}$ In the absence of long-term results from large patient registries, the availability of long-term safety data from clinical trials of therapeutics in psoriasis is particularly important.

To address this need, the cumulative long-term safety experience with adalimumab in all patients treated with one or more doses in any treatment regimen in all trials of moderate to severe chronic plaque psoriasis was assessed in an integrated analysis of data that were collected on three occasions from 15 April 2007 through 6 November 2009. In addition, the cumulative data from 1403 patients who were exclusively treated with adalimumab $40 \mathrm{mg}$ every other week (eow) available as of 25 June 2007, and 14 April 2010, were analyzed in the same fashion. This report represents the most comprehensive review of adalimumab safety in moderate to severe psoriasis to date.

\section{Methods}

Clinical Trials and Independent Data Sources Included in this Analysis

This integrated analysis included data from 13 psoriasis clinical trials comprising four phase II, three phase II/III, two phase III, three phase IIIb, and one phase IV clinical trials (see table 1, Supplementary Digital Content 1, http://links.adisonline. com/DYZ/A2). ${ }^{[7-16]}$ Most patients from the randomized clin- ical trials continued treatment with adalimumab in a long-term, open-label extension study. These trials were varied in their design, with broad geographic distribution and durations ranging from 12 weeks to $>5$ years.

\section{Patients}

The following main inclusion criteria applied to the feeder trials in this analysis: (i) male and female patients aged $\geq 18$ years with a clinical diagnosis of psoriasis for $\geq 6$ months; (ii) body surface area (BSA) affected $\geq 5 \%$ (M02-528 and M02538) or $\geq 10 \%$ (PRIDE, M04-688, REVEAL, CHAMPION); and (iii) Psoriasis Area and Severity Index (PASI) score $\geq 8$ (M02-538), $\geq 10$ (CHAMPION), or $\geq 12$ (REVEAL, M04-688, PRIDE). Patients were screened for latent tuberculosis (TB); any patient who demonstrated evidence of prior TB infection following purified protein derivative (PPD) testing and chest $\mathrm{X}$-ray was allowed to participate in a study provided that prophylactic treatment was started before study medication was administered. Patients who previously received TB prophylaxis were not required to repeat treatment. Race was described per patient selection on study form.

Corticosteroid-free shampoos, bland (without $\beta$ - or $\alpha$-hydroxy acids) emollients, and low-potency (class VI or class VII) topical corticosteroids on the palms, soles, face, inframammary area, and groin only were permitted. The BELIEVE trial included 366 patients who were treated with adalimumab and a topical therapy (calcipotriol/betamethasone).

Exclusion criteria included prior exposure to any anti-TNF therapy, including adalimumab, except in extension trials where adalimumab could be continued, and in M10-238 and PRIDE, in which all prior TNF antagonists were permitted.

The 'Every Other Week Population' (EOW Population) was defined as all patients who had received one or more doses of adalimumab, and who either started adalimumab $40 \mathrm{mg}$ eow beginning 1 week after an $80 \mathrm{mg}$ initial dose or started on placebo treatment and switched to adalimumab $40 \mathrm{mg}$ eow. The EOW Population included 1403 patients from five randomized, placebo-controlled, clinical trials (M02-528, M02-529, REVEAL, CHAMPION, M03-658).

The 'All Adalimumab Treatment Population' (AAT Population) was defined as all patients in all trials in the adalimumab psoriasis clinical development program who had received one or more doses of adalimumab as part of any treatment regimen.

The AAT Population included 422 patients (14.0\%) who were treated with $40 \mathrm{mg}$ eow without an $80 \mathrm{mg}$ starting dose (cumulative exposure $=988.7 \mathrm{PYs}$; mean $=2.3 \mathrm{PYs} /$ patient $), 198$ patients who received $40 \mathrm{mg}$ weekly dosing (total exposure $=486.5 \mathrm{PYs}$; 
mean $=2.5 \mathrm{PYs} /$ patient), and 62 patients who received $80 \mathrm{mg}$ eow dosing (total exposure $=167.6 \mathrm{PYs}$; mean $=2.7 \mathrm{PYs} /$ patient) . Together with the regimen described for the EOW Population, these dosing regimens accounted for the greatest contributions to the total cumulative adalimumab exposure in the AAT Population.

Patients who completed the phase II trial, M02-528, and its open-label extension, M02-529, could have had up to 60 weeks of adalimumab exposure. Under certain conditions, they could be eligible to gain adequate additional exposure in the M03-658 continuation study, for a potential exposure of $>260$ patientweeks ( $>5.0$ PYs) of adalimumab exposure per patient.

Similarly, patients in M02-538, M03-596, REVEAL, and CHAMPION could each potentially have experienced up to 5 PYs of adalimumab exposure, depending, for example, on the trial in which they participated, their clinical efficacy responses, and protocol-specified treatment regimens. A total of $1696 \mathrm{pa}-$ tients were treated with one or more doses of adalimumab in the early phase II and III trials from which participants could potentially be eligible for enrollment in M03-658.

The 1403 patients whose data were included in the EOW Population participated in these early studies, and had safety data available prior to 25 June 2007. For this reason, the cumulative number of patients in the EOW Population did not change.

In contrast, patients who enrolled in later trials were not eligible to enter M03-658, and did not have the potential to gain as much adalimumab exposure. Patients who participated in M04-688, and its open-label extension, M04-702, could experience up to 52 weeks of adalimumab exposure; however, the 1151 patients who were treated with one or more doses of adalimumab in M10-238, PRIDE, BELIEVE, and M10-405 were limited to a maximum possible exposure of 16-28 weeks, depending on the trial in which they were enrolled.

Overall, the 1696 patients who participated in the six early phase II and III trials represented $56.3 \%$ of the 3010 patients in the AAT Population by November 2009, and could potentially have experienced a maximum of up to 16-fold more adalimumab exposure than patients in the four most recent trials. The balance comprised primarily the patients in the seven most recent studies.

\section{Study Treatments}

Adalimumab was administered subcutaneously in all trials. The adalimumab dosing regimens used by the greatest numbers of patients included in this analysis were as follows: (i) $80 \mathrm{mg}$ initial dose at baseline, then $40 \mathrm{mg}$ eow beginning 1 week later
(40 mg eow dosing; this regimen is indicated for use in moderate to severe chronic plaque psoriasis); (ii) $40 \mathrm{mg}$ eow, started either 2 weeks after an $80 \mathrm{mg}$ initial dose, or without a loading dose ( $40 \mathrm{mg}$ eow no load); (iii) $80 \mathrm{mg}$ at weeks 0 and 1, then $40 \mathrm{mg}$ weekly beginning at week 2 (40 mg weekly dosing); (iv) $80 \mathrm{mg}$ eow; (v) $40 \mathrm{mg}$ weekly beginning after a period of $40 \mathrm{mg}$ eow (dosage escalation); and (vi) $40 \mathrm{mg}$ eow as re-treatment after a period of withdrawal. In some trials, one of the above dosing regimens was followed by one or more of the others. Some studies included treatment with adalimumab following prior treatment with methotrexate, etanercept, or narrow-band UVB, or in combination with a topical therapy.

\section{Methodology for the Integrated Analysis}

All available safety data from the AAT Population were collected and pooled on 15 April 2007, and again on 6 November 2008, and 6 November 2009, for administrative reasons. These sets of cumulative data were analyzed for this report. All available safety data from the EOW Population were collected and pooled on 25 June 2007, and again on 14 April 2010.

Adverse events from the placebo-controlled periods of five placebo-controlled trials (M02-528, REVEAL, M04-688, M04-716, M10-405) were also analyzed. This analysis included all patients randomized to placebo at study baseline in these five studies $(\mathrm{n}=572)$, and matching patients receiving adalimumab $40 \mathrm{mg}$ eow (after an $80 \mathrm{mg}$ loading dose; $\mathrm{n}=1188$ ).

Adverse events that occurred after the first dose of adalimumab and up to 70 days after the last dose were considered treatment emergent. For patients with a protocol-designed gap in treatment, adverse events observed $>70$ days after the last dose of adalimumab prior to the gap, and before initiation of the next adalimumab treatment period, were not considered treatment emergent. All adverse events were described using MedDRA (Medical Dictionary for Regulatory Activities) Preferred Terms. MedDRA is a standardized medical terminology used to classify adverse event information associated with the use of biopharmaceuticals.

The standardized mortality ratio was calculated as the ratio of observed deaths to expected deaths (estimation based on PYs of treatment from the WHO age- and country-specific mortality tables [years 1997-2002]). ${ }^{[17]}$ Standardized incidence ratios (SIR) for cancer rates, the ratio of the observed number of malignancies divided by the expected number of malignancies, were calculated using cancer rates from The National Cancer Institute (NCI) Surveillance, Epidemiology, and End Results (SEER) database for 1993-2001. As the NCI SEER database does not include rates of non-melanoma skin cancer (NMSC), 
expected rates of NMSC in the general population were taken from a 1977-8 NCI survey in the US. Basal cell carcinoma (BCC) and squamous cell carcinoma (SCC) comparator rates were taken from the Arizona and Minnesota databases. ${ }^{[5]}$

\section{Results}

The 13 psoriasis clinical trials included in this analysis included a wide range of entry criteria, washout period durations, prior treatment entry criteria, treatment regimens, concomitant medications, changes in adalimumab dosing, dose interruptions, re-treatment conditions, and geographic locations (see table 1, SDC).

\section{Exposure}

As of 25 June 2007 and 14 April 2010, the 1403 patients who initiated adalimumab with $40 \mathrm{mg}$ eow dosing had a cumulative exposure of 1883.5 PYs and 2854.1 PYs, respectively, and an average exposure per patient of 1.3 PYs (16.1 patient-months) and 2.0 PYs (24.4 patient-months), respectively (figure 1b).

\section{Demographics}

The baseline demographics and clinical characteristics of these patients were typical of those who have participated in most trials of biologic therapeutics in moderate to severe psoriasis (table I).

A large percentage of patients enrolled in these trials exhibited risk factors associated with obesity and metabolic syndrome, including elevated BMI, blood pressure, and triglycerides. ${ }^{[18]}$ In the AAT Population, $42.3 \%$ of patients had $\mathrm{BMI} \geq 30,51.7 \%$ had systolic $\mathrm{BP} \geq 130 \mathrm{mmHg}$ or diastolic BP $\geq 85 \mathrm{mmHg}$, and $46.9 \%$ had triglyceride levels $\geq 1.7 \mathrm{mmol} / \mathrm{L}$.

The M03-658 study design allowed many participants in early trials to accrue long durations of adalimumab exposure between 15 April 2007 and 6 November 2008, and total adalimumab exposure increased from 2424.7 PYs to 4351.9 PYs (increase: 1927.2 PYs; $79.5 \%$ ), respectively, while the cumulative number of patients only increased from 1819 to $2197(n=378$; $20.8 \%$ ), respectively (figure 1a). As a consequence, from April 2007 to November 2008, the average patient exposure to adalimumab in the AAT Population increased from 1.3 PYs (16.0 patient-months) to 2.0 PYs (23.8 patient-months) [figure 1a].

However, during the year between 6 November 2008 and 6 November 2009, some of the patients enrolled in the earlier trials completed study participation, and data for patients who participated in the later trials of 16-28 weeks duration became available. The net result was an increase in total adalimumab exposure from 4351.9 PYs to 4844.7 PYs (increase: 492.8 PYs; $11.3 \%$ ), with an increase in the cumulative number of patients from 2197 to 3010 (increase: $\mathrm{n}=813 ; 37.0 \%$ ). As a result, from November 2008 to November 2009, the average patient exposure to adalimumab in the AAT Population decreased from 2.0 PYs (23.8 patient-months) to 1.6 PYs (19.3 patient-months).

\section{Adverse Events}

The adverse events that occurred in $\geq 5 \%$ of patients were nasopharyngitis, upper respiratory infection, and headache, in

Table I. Baseline demographics and clinical characteristics of the patients in the adalimumab psoriasis clinical trials program ${ }^{a}$

\begin{tabular}{lll}
\hline Demographics and characteristics & AAT Population, 6 November 2009 $(\mathrm{N}=3010)$ & EOW Population, 4 April 2010 (N=1403) \\
\hline Age (y) & $44.7(12.7)$ & $44.3(13.1)$ \\
Male (\%) & 66.8 & 66.9 \\
Caucasian (\%) & 87.5 & 91.4 \\
Duration of psoriasis (y) & $19.0(11.7)$ & $18.3(11.6)$ \\
Bodyweight (kg) & $89.0(22.0)$ & $91.8(22.7)$ \\
BSA affected (\%) & $28.1(18.7)$ & $26.5(15.9)$ \\
PASI score & $18.8(8.5)$ & $18.9(7.1)$ \\
Patients with PsA (\%) & $28.6^{\mathrm{c}}$ & 27.2 \\
BMI $\geq 30(\%)$ & 42.3 & 48.1
\end{tabular}

a Values are expressed as mean (SD) unless indicated otherwise.

b In some cases, data were unavailable for up to $1 \%$ of patients.

c $n=2034$; history of PsA was not collected in M03-688.

AAT=All Adalimumab Treatment; BMI=body mass index; BSA=body surface area; EOW=Every Other Week; PASI=Psoriasis Area Severity Index; PsA $=$ psoriatic arthritis. 

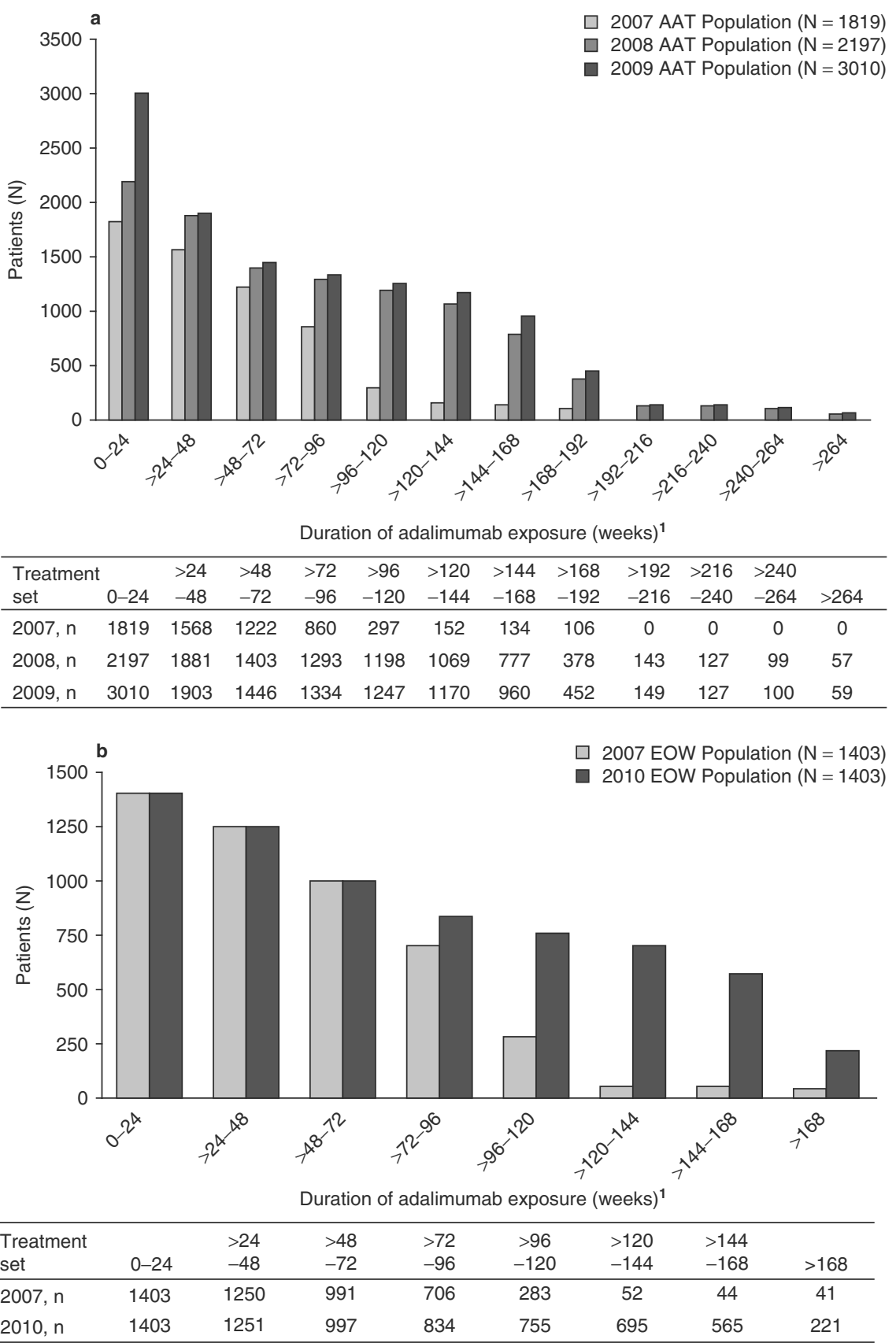

Fig. 1. Duration of exposure to adalimumab of patients in the All Adalimumab Treatment Population (AAT Population) [a] and the Every Other Week Population (EOW Population) [b]. (a) For the AAT Population, 1819 patients were included in the April 2007 dataset, 2197 patients were included in the November 2008 dataset, and 3010 were included in the 2009 dataset. (b) For the EOW Population, 1403 patients were included in both the 2007 and 2010 datasets. Numbers of patients in each interval $(n)$ are shown in the tables below the figures. 1 Patients in a given duration-of-exposure interval are also included in all intervals of lesser duration of exposure.

both the AAT Population (figure 2a) and the EOW Population (figure 2b) for all groups. In general, the incidence rates of all common adverse events decreased with increased mean perpatient adalimumab exposure with the exception of a small increase in nasopharyngitis (20.6 events/100 PYs to 21.0 events/ 100 PYs) between the 2007 and 2008 AAT Population datasets, respectively. The converse was also true, as incidence rates remained the same, or slightly increased, as mean per-patient exposure decreased between November 2008 (2.0 PYs/patient) and November 2009 (1.6 PYs/patient) for all adverse events that occurred in $\geq 5 \%$ of patients at both data collection cutoff dates in the AAT Population (figure 2a). 
During the placebo-controlled periods of the clinical trials, rates of any adverse event, infectious adverse events, serious adverse events, NMSC, and allergic reaction were higher for adalimumab-treated patients $(\mathrm{n}=1188 ; 370.5$ total PYs of exposure) as compared with placebo-treated patients $(n=572$; 173.0 total PYs of exposure; table II). All other adverse events of interest were similar across both treatment groups during the placebo-controlled periods. There were no deaths or cases of lymphoma, demyelinating disease, or lupus-like syndrome in either group during the placebo-controlled periods.

Incidence rates of any adverse event, any infectious adverse event, serious adverse event, serious infectious adverse event, and malignancy were generally stable with increased adalimumab exposure for both the AAT and the EOW Populations. The incidence rates of these adverse events of interest were greatest for patients with $\leq 24$ weeks of adalimumab exposure in all datasets (tables III and IV; figures 3 and 4), and similar to those observed during the placebo-controlled periods (table II). In the AAT Population, an increase in incidence rates was observed during a single 24-week period for serious adverse events (weeks >192-216) due to events of nasal septum deviation, urinary incontinence, renal failure chronic, rectal cancer, humerus fracture, chest discomfort, and umbilical hernia (figure 3a). Apparent increases in incidence rates in serious infectious adverse events during weeks $>216-240$ (figure $3 b$ ) and in malignancies during weeks $>192-216$ (figure $3 \mathrm{c}$ ) were each due to two events. Overall rates of any adverse event and infectious adverse event were lower for the AAT and EOW Populations than those observed during the placebo-controlled phases of the trials.

\section{Special Adverse Events of Interest}

Deaths

There were eight deaths reported as of 6 November 2009 in the psoriasis clinical trials program (table III). In this regard, one death was reported by the investigator as the result of two fatal adverse events. This caused the total number of fatal adverse events $(n=9)$ to exceed the total number of deaths $(n=8)$ [table V]. Narrative details of the deaths are shown in table V. A standardized mortality ratio of 0.31 (95\% CI 0.13 , 0.62 ) with an upper limit of the $95 \% \mathrm{CI}<1.0$ suggests that the WHO database used for comparison in this analysis had mortality rates greater than those patients exposed to adalimumab in psoriasis clinical trials.

\section{Serious Infections}

In the 2009 AAT Population and the 2010 EOW Population, overall there were 80 serious infectious events in 67 patients (1.65 events/100 PYs) and 39 serious infectious events in 29 patients (1.37 events/100 PYs), respectively. Cellulitis was the most common serious infectious adverse event in both the 2009 AAT Population ( $\mathrm{n}=13 ; 0.27$ events/100 PYs) and the 2010 EOW Population ( $\mathrm{n}=8 ; 0.28$ events/100 PYs). Pneumonia was the second most common serious infection in the 2009 AAT Population ( $n=9 ; 0.19$ events/100 PYs). Together, cellulitis and pneumonia accounted for $27.5 \%$ of all serious infectious events. All other serious infections were reported at a rate of $\leq 0.10$ events/100 PYs for patients in the AAT and EOW Populations.

Opportunistic Infections (Excluding Tuberculosis)

In the 2009 AAT Population, 20 events of opportunistic infections were reported ( 0.41 events/100 PYs). None was classified as a serious adverse event. There were nine oral candidiasis events, eight candidiasis events, one oropharyngeal candidiasis event, one coccidiodomycosis event, and one cytomegalovirus infection.

The coccidiodomycosis event involved a 71-year-old White female living in an endemic area of southwestern US; the patient was an ex-tobacco user with a 45-pack per year smoking history. The event was classified as 'mild' by the investigator; the patient had been receiving adalimumab $40 \mathrm{mg}$ eow ( 92 days) at the time of event onset; event duration was 16 days.

The event of cytomegalovirus infection involved a 27 -yearold White female who discontinued adalimumab $40 \mathrm{mg}$ eow plus topical vehicle after 7 days of treatment due to pregnancy. The event occurred approximately 2 months after study drug discontinuation, and was not classified as serious.

\section{Tuberculosis}

$244(8.1 \%)$ of 2991 patients had a positive PPD skin test in the 2009 AAT Population at baseline. Seven cases of TB were reported (0.14 events/100 PYs) as follows: one disseminated TB, three pulmonary TB, and three TB. TB represented $8.8 \%$ of serious infectious adverse events and $1.7 \%$ of serious adverse events. Five of the TB cases were in Asian males. There was no evidence of geographic clustering as none of the patients resided in the same country during study participation. Prophylaxis compliance issues were noted in the medical records of all three cases of TB reactivation in PPD-positive patients. Narrative details of the TB cases are shown in table VI.

\section{Demyelinating Disease}

One case of demyelinating disease occurred as of November 2009 in a 45-year-old White female with multiple sclerosis and sensory dyesthesias on the right side of the face with vision changes (diagnosed by MRI) and reported to have no known risk factors. The event was not classified as a serious adverse event by the investigator (one event; 0.02 and 0.04 events/100 PYs, in the 2009 AAT and 2010 EOW Populations, respectively). The patient received adalimumab $40 \mathrm{mg}$ eow (total exposure $=$ 
48 weeks, with treatment interruption); total participation time 742 days at time of onset.

\section{Lupus and Lupus-Like Syndrome}

Two events of cutaneous lupus and one event of anti-doublestranded DNA antibody were reported as of November 2009 in the AAT Population (incidence rate $=0.06$ events $/ 100$ PYs). None was a serious adverse event.

\section{Allergic Reactions}

As of November 2009, 51 allergic reactions were reported in the AAT Population, with an incidence rate of 1.05 events/100 PYs. There were 34 events of urticaria, 11 of hypersensitivity, 2 of swelling face, 1 of anaphylactoid reaction, 1 of anaphylactic shock, 1 of swollen tongue, and 1 of angioedema.

The one case of anaphylactic shock was reported in a 42year-old White male on day 65 of treatment after he was stung

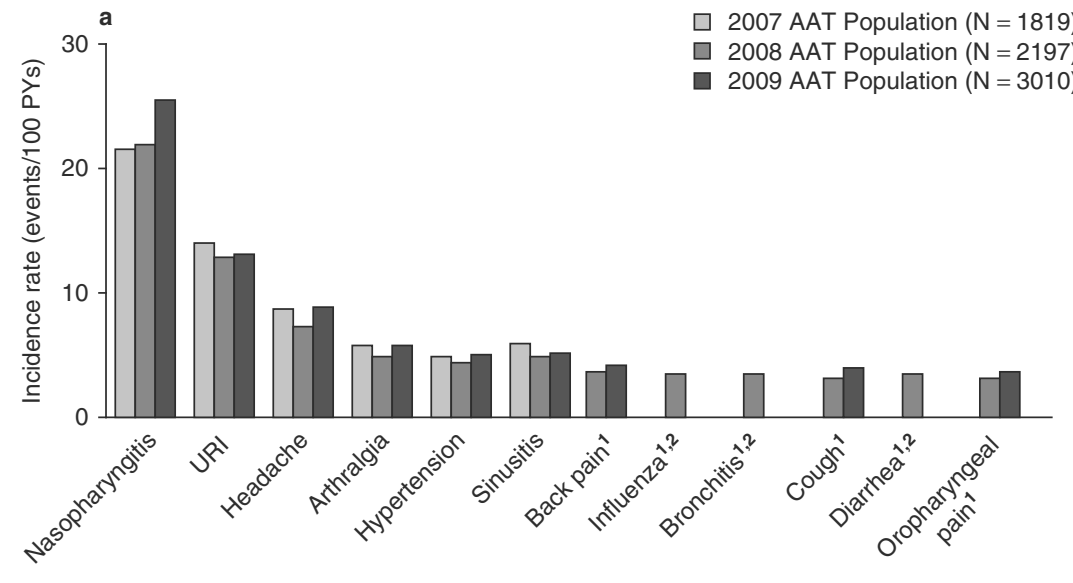

\begin{tabular}{lccccccccccccc}
\hline \multicolumn{11}{l}{ Treatment set } & Incidence rate (events/100 PYs) \\
\hline 2007 & 20.6 & 13.5 & 8.4 & 5.6 & 4.7 & 5.7 & - & - & - & - & - & - \\
2008 & 21.0 & 12.3 & 7.0 & 4.7 & 4.1 & 4.7 & 3.4 & 3.3 & 3.4 & 3.1 & 3.3 & 3.0 \\
2009 & 24.4 & 12.4 & 8.4 & 5.4 & 4.8 & 4.9 & 4.0 & - & - & 3.7 & - & 3.5 \\
\hline
\end{tabular}
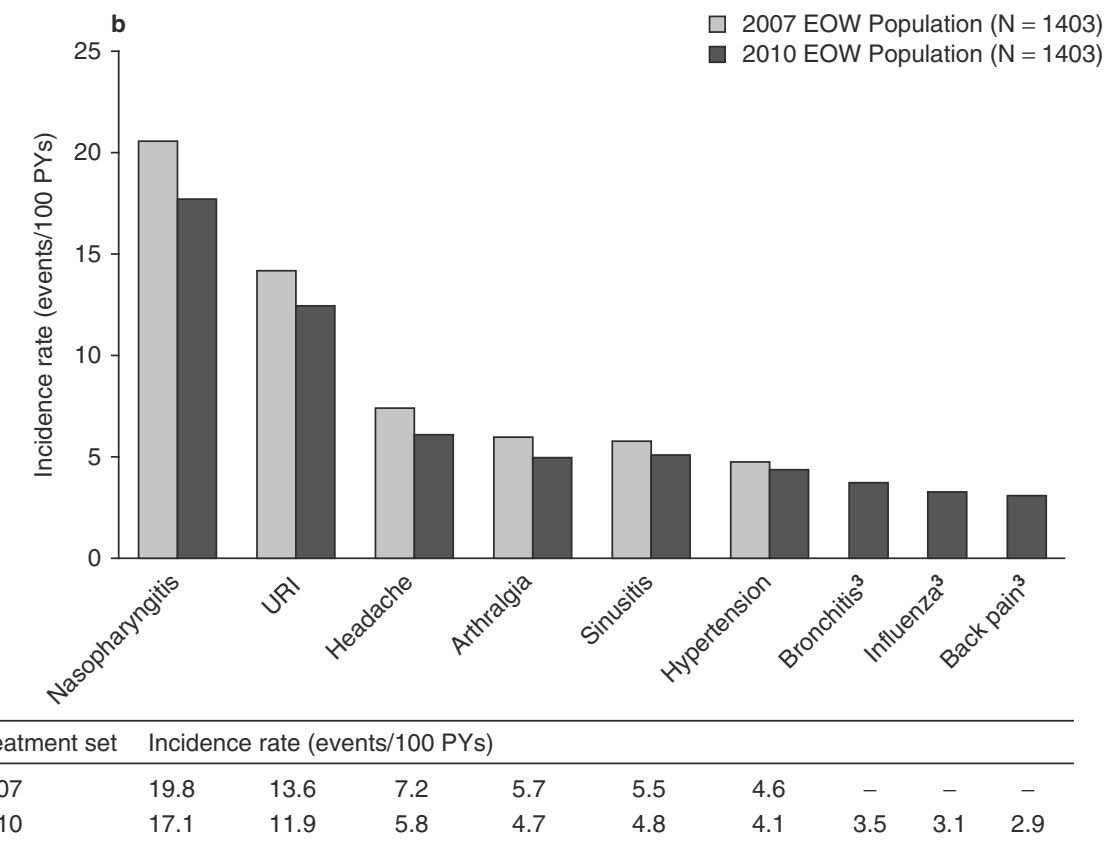

Fig. 2. Adverse events occurring in $\geq 5 \%$ of patients in the All Adalimumab Treatment Population (AAT Population) [a] and the Every Other Week Population (EOW Population) [b]. Nasopharyngitis, upper respiratory infection, and headache were the most commonly occurring adverse events for all treatment sets. 1 Less than $5 \%$ of patients were affected in the 2007 AAT Population. 2 Less than $5 \%$ of patients were affected in the 2009 AAT Population. 3 Less than $5 \%$ of patients were affected in the 2007 EOW Population. PYs = patient years; URI = upper respiratory infection; - indicates less than $5 \%$ of patients in the treatment set experienced the adverse event. 
Table II. Adverse events of interest during the placebo-controlled periods of adalimumab psoriasis clinical trials

\begin{tabular}{|c|c|c|c|c|}
\hline \multirow[b]{3}{*}{$\mathrm{N}$} & \multicolumn{4}{|c|}{ Placebo-controlled phase } \\
\hline & \multicolumn{2}{|l|}{ placebo } & \multicolumn{2}{|l|}{ adalimumab } \\
\hline & 572 & & 1188 & \\
\hline Exposure (PYs) & 173.0 & & 370.5 & \\
\hline Mean exposure per patient (mo) & 3.6 & & 3.7 & \\
\hline Adverse event & Events & Incidence (events/100 PYs) & Events & Incidence (events/100 PYs) \\
\hline Any $A E$ & 964 & 557.2 & 2434 & 657.0 \\
\hline Infectious AE & 200 & 115.6 & 572 & 154.4 \\
\hline Serious $\mathrm{AE}$ & 13 & 7.52 & 32 & 8.64 \\
\hline Serious infectious $\mathrm{AE}$ & 5 & 2.89 & 9 & 2.43 \\
\hline Malignancies (excluding NMSC) & 2 & 1.16 & 3 & 0.81 \\
\hline NMSC & 1 & 0.58 & 5 & 1.35 \\
\hline Lymphoma & 0 & 0 & 0 & 0 \\
\hline Fatal AE & 0 & 0 & 0 & 0 \\
\hline Opportunistic infections (excluding TB) & 0 & 0 & 1 & 0.27 \\
\hline TB & 0 & 0 & 0 & 0 \\
\hline Congestive heart failure & 0 & 0 & 1 & 0.27 \\
\hline Allergic reaction & 1 & 0.58 & 7 & 1.89 \\
\hline Demyelinating disease & 0 & 0 & 0 & 0 \\
\hline Lupus-like syndrome & 0 & 0 & 0 & 0 \\
\hline
\end{tabular}

$\mathbf{A E}=$ adverse event; $\mathbf{N M S C}=$ nonmelanoma skin cancer; $\mathbf{P Y} \mathbf{s}=$ patient years; $\mathbf{T B}=$ tuberculosis.

by a hornet. The study drug was not interrupted and the patient completed the study uneventfully.

\section{Malignancies}

The incidence rates for malignancies (excluding NMSC) were $0.58,0.64$, and 0.72 events/100 PYs for the April 2007, November 2008, and November 2009 AAT Populations, respectively. Using the NCI SEER database, the SIRs (95\% CI) for malignancies (excluding NMSC) were $0.80(0.41,1.39), 0.89$ $(0.57,1.32)$, and $0.90(0.60,1.29)$ for the 2007,2008 , and 2009 datasets, respectively.

The incidence rates for NMSC were 0.78, 0.71, and 0.70 events/100 PYs for the 2007, 2008, and 2009 AAT Population datasets, respectively. Relative to the 1978-97 NCI Survey, the SIR (95\% CI) for NMSC in the AAT Population was 1.81 (0.09, $2.82)$ for the 2007 dataset, $1.59(1.07,2.26)$ for the 2008 dataset, and $1.51(1.04,2.11)$ for the 2009 dataset. SIR results for NMSC were recently reported for the 2007 AAT Population for psoriasis, as well as for similar results from five other indications. ${ }^{[5]}$ Relative to the $1977-8$ NCI study database, the SIR (95\% CI) for SCC (but not BCC) in psoriasis (3.84 [1.54, 7.92]) was significantly greater than 1.0 . The SIR was not signif- icantly greater than 1.0 when either the Arizona or Minnesota rates were employed for comparison. ${ }^{[5]}$ In a more recent cohort from psoriasis clinical trials, 2944 patients with 5684 PYs of exposure through 8 December 2009, and a mean exposure of 1.9 PYs, had an SIR (95\% CI) for overall NMSC, BCC, and SCC of $1.52(1.05,2.12), 1.36(0.88,2.00)$, and $2.29(1.04,4.34)$, indicating an absolute decrease in the SCC SIR. Nonetheless, the lower limits of the overall NMSC and SCC 95\% CIs slightly exceeded 1.0, suggesting that these differences were significant. Interpretation of these results is complicated by the lack of availability of more recent reference data, and the well known substantial increase in NMSC incidence rates since the late 1970s. ${ }^{[19,20]}$

In the adalimumab psoriasis clinical program, there were three malignant melanoma cases as of April 2007, seven as of November 2008, and nine as of November 2009. Narrative details of the malignant melanoma cases are shown in table VII.

One case of lymphoma was observed in the 2009 AAT Population in a 43-year-old White male. At screening and baseline visits, the patient had an elevated absolute lymphocyte count with abnormal/immature lymphocytoid cells seen at base- 
line. A diagnosis of mantle cell lymphoma, stage IV with bone marrow involvement was made. At the time of onset, the patient had been treated with adalimumab $40 \mathrm{mg}$ eow for 59 days.

\section{Major Adverse Cardiovascular Events and Congestive Heart Failure}

In the 2007, 2008, and 2009 AAT Populations, the incidence rates of coronary artery disease were $0.25,0.18$, and 0.25 events/100 PYs, respectively, and of myocardial infarction were $0.21,0.16$, and $\leq 0.1$ events/100 PYs, respectively. Multiple recent reports have shown an association between psoriasis and an increased risk of cardiovascular disease and cardiovascular death in patients with severe disease in population databases. ${ }^{[21,22]}$ MACE (major adverse cardiovascular event) is defined as nonfatal myocardial infarction, nonfatal stroke, or cardiovascular death. During the initial placebo-controlled periods in three adalimumab psoriasis registration studies, one MACE was reported during $294 \mathrm{PYs}$ of adalimumab exposure (incidence rate [95\% CI]: 0.34 events/100 PYs $[0.01,1.90])$, and one MACE was reported during $148 \mathrm{PYs}$ of placebo exposure (incidence rate $[95 \%$ CI]: 0.68 events/100 PYs $[0.02,3.76])$. Among the seven adalimumab registration studies, 15 MACE (six nonfatal myocardial infarctions, four nonfatal strokes, five cardiovascular deaths) were reported during $4175 \mathrm{PYs}$ of adalimumab exposure (incidence rate [95\% CI]: 0.36 events/100 PYs [0.20, 0.59]).

The incidence rates of CHF were $0.04,0.21$, and 0.23 events/ 100 PYs in the 2007, 2008, and 2009 AAT populations, respectively. Expansion of the MedDRA Preferred Term 'congestive heart failure' search criteria in November 2008 resulted in the inclusion of events of pulmonary edema (considered a

Table III. Adverse events of interest in the All Adalimumab Treatment (AAT) Population

\begin{tabular}{|c|c|c|c|c|c|c|}
\hline \multirow[b]{3}{*}{$\mathrm{N}$} & \multicolumn{6}{|c|}{ AAT Population } \\
\hline & \multicolumn{2}{|c|}{ April 2007} & \multicolumn{2}{|c|}{ November 2008} & \multicolumn{2}{|c|}{ November 2009} \\
\hline & 1819 & & 2197 & & 3010 & \\
\hline Exposure (PYs) & 2424.7 & & 4351.9 & & 4844.7 & \\
\hline Mean exposure per patient (mo) & 16.0 & & 23.8 & & 19.3 & \\
\hline Adverse event & Events & $\begin{array}{l}\text { Incidence } \\
\text { (events/100 PYs) }\end{array}$ & Events & $\begin{array}{l}\text { Incidence } \\
\text { (events/100 PYs) }\end{array}$ & Events & $\begin{array}{l}\text { Incidence } \\
\text { (events/100 PYs) }\end{array}$ \\
\hline Any AE & 7219 & 297.5 & 12000 & 275.7 & 15177 & 313.3 \\
\hline Infectious AE & 2036 & 83.9 & 3489 & 80.2 & 4301 & 88.8 \\
\hline Serious $\mathrm{AE}$ & 158 & 6.51 & 314 & 7.22 & 405 & 8.36 \\
\hline Serious infectious $\mathrm{AE}$ & 32 & 1.32 & 60 & 1.38 & 80 & 1.65 \\
\hline Malignancies (excluding NMSC) & 14 & 0.58 & 28 & 0.64 & 35 & 0.72 \\
\hline NMSC & 19 & 0.78 & 31 & 0.71 & 34 & 0.70 \\
\hline Lymphoma & 0 & 0 & 0 & 0 & 1 & 0.02 \\
\hline Fatal AE & 3 & 0.12 & 5 & 0.11 & 9 & 0.19 \\
\hline Opportunistic infections (excluding TB) & 5 & 0.21 & 12 & 0.28 & 20 & 0.41 \\
\hline TB & 3 & 0.12 & 6 & 0.14 & 7 & 0.14 \\
\hline Congestive heart failure & 1 & 0.04 & 9 & 0.21 & $11^{\mathrm{a}}$ & 0.23 \\
\hline Allergic reaction & 4 & 0.16 & $37^{\mathrm{b}}$ & 0.85 & $51^{\mathrm{b}}$ & 1.05 \\
\hline Demyelinating disease & 0 & 0 & 1 & 0.02 & 1 & 0.02 \\
\hline Lupus-like syndrome & 1 & 0.04 & 1 & 0.02 & 3 & 0.06 \\
\hline
\end{tabular}

a Search criteria for the MedDRA Preferred Term 'congestive heart failure' were expanded for the November 2009 dataset to include events with a clear diagnosis or indication of congestive heart failure reported (i.e. symptoms indicated as secondary to congestive heart failure or action taken pertinent to the diagnosis of congestive heart failure). There were 11 cases of congestive heart failure. The events were cardiac failure congestive (8), pulmonary edema (2), and hepatic congestion (1).

b Search criteria for the MedDRA Preferred Term 'allergic reaction' were expanded to include events developed in association with the injection of adalimumab and not caused by another agent/drug. In the 2009 dataset, 39 patients reported 51 allergic reactions. The events were hypersensitivity (11), anaphylactoid reaction (1), anaphylactic shock (1), urticaria (34), swelling face (2), swollen tongue (1), and angioedema (1).

$\underline{\mathbf{A E}}=$ adverse event; MedDRA = Medical Dictionary for Regulatory Activities; NMSC = nonmelanoma skin cancer; $\mathbf{P Y} \mathbf{s}=$ patient years; $\mathbf{T B}=$ tuberculosis. 
Table IV. Adverse events of interest in the Every Other Week (EOW) Population

\begin{tabular}{|c|c|c|c|c|}
\hline \multirow[b]{3}{*}{ N } & \multicolumn{4}{|c|}{ EOW Population } \\
\hline & \multicolumn{2}{|c|}{ June 2007} & \multicolumn{2}{|c|}{ April 2010} \\
\hline & 1403 & & 1403 & \\
\hline Exposure (PYs) & 1883.5 & & 2854.1 & \\
\hline Mean exposure per patient (mo) & 16.1 & & 24.4 & \\
\hline Adverse event & Events & Incidence (events/100 PYs) & Events & Incidence (events/100 PYs) \\
\hline Any $A E$ & 5220 & 277.1 & 7036 & 246.5 \\
\hline Infectious AE & 1613 & 85.6 & 2133 & 74.7 \\
\hline Serious $\mathrm{AE}$ & 119 & 6.32 & 196 & 6.87 \\
\hline Serious infectious $A E$ & 25 & 1.33 & 39 & 1.37 \\
\hline Malignancies (excluding NMSC) & 10 & 0.53 & 17 & 0.60 \\
\hline NMSC & 14 & 0.74 & 21 & 0.74 \\
\hline Lymphoma & 0 & 0 & 0 & 0 \\
\hline Fatal AE & 1 & 0.05 & 4 & 0.14 \\
\hline Opportunistic infections (excluding TB) & 5 & 0.27 & 7 & 0.25 \\
\hline TB & 4 & 0.21 & 5 & 0.18 \\
\hline Congestive heart failure & 1 & 0.05 & $6^{\mathrm{a}}$ & 0.21 \\
\hline Allergic reaction & 6 & 0.32 & $15^{\mathrm{b}}$ & 0.53 \\
\hline Demyelinating disease & 1 & 0.05 & 1 & 0.04 \\
\hline Lupus-like syndrome & 0 & 0 & 0 & 0 \\
\hline
\end{tabular}

a Search criteria for the MedDRA Preferred Term 'congestive heart failure' were expanded after June 2007 and prior to April 2010 to include events with a clear diagnosis or indication of congestive heart failure reported (i.e. symptoms indicated as secondary to congestive heart failure or action taken pertinent to the diagnosis of congestive heart failure).

b Search criteria for the MedDRA Preferred Term 'allergic reaction' were expanded after June 2007 and prior to April 2010 to include events developed in association with the injection of adalimumab and not caused by another agent/drug.

$\mathbf{A E}=$ adverse event; MedDRA = Medical Dictionary for Regulatory Activities; NMSC $=$ nonmelanoma skin cancer; $\mathbf{P Y} \mathbf{s}=$ patient years; $\mathbf{T B}=$ tuberculosis.

serious adverse event) and hepatic congestion (not considered serious); there were two cases of pulmonary edema and one case of hepatic congestion as of November 2009.

\section{Discussion}

This integrated analysis of data from 3010 psoriasis patients with $>4800$ PYs of adalimumab exposure indicated that rates of treatment-emergent serious adverse events, serious infections, and malignancies in patients treated with adalimumab were low, and most serious adverse events decreased with increased mean per-patient exposure to adalimumab. This notion is supported by several lines of evidence. First, the incidence of serious adverse events, serious infectious adverse events, and malignancies did not increase for intervals that included patients with greater exposure. Second, the rates of more common adverse events, which are less sensitive to small changes in event numbers with time, did not increase between timepoints in either the AAT Population, or the EOW Population. In particular, data for the latter represent safety information from the same 1403 patients at two different times. The incidence rates of virtually all common adverse events that occurred in $>5 \%$ of patients decreased with increased adalimumab exposure.

In addition, treatment-emergent adverse event incidence rates were similar regardless of whether analysis was restricted to patients who received the indicated dosing of adalimumab (40 mg eow dosing) or included patients who received adalimumab in a broad variety of other dosing regimens, including weekly dosing, immediately following other psoriasis treatments, or in combination with other psoriasis therapies.

The practical relevance of incidence rates expressed as events/100 PYs is not often addressed outside of the literature on clinical trials and epidemiology studies. One event/100 PYs is equivalent to a $1 \%$ chance of an event occurring to a patient who receives uninterrupted treatment for 1 year. To provide 
context to such values, the difference in the serious infectious adverse event incidence rates between the 2007 (1.32 events/ 100 PYs) and 2009 (1.65 events/100 PYs) ATT Population data- sets represented an equivalent difference in risk of a $1.32 \%$ versus a $1.65 \%$ likelihood that one patient would have experienced one event during the course of 1 year of uninterrupted
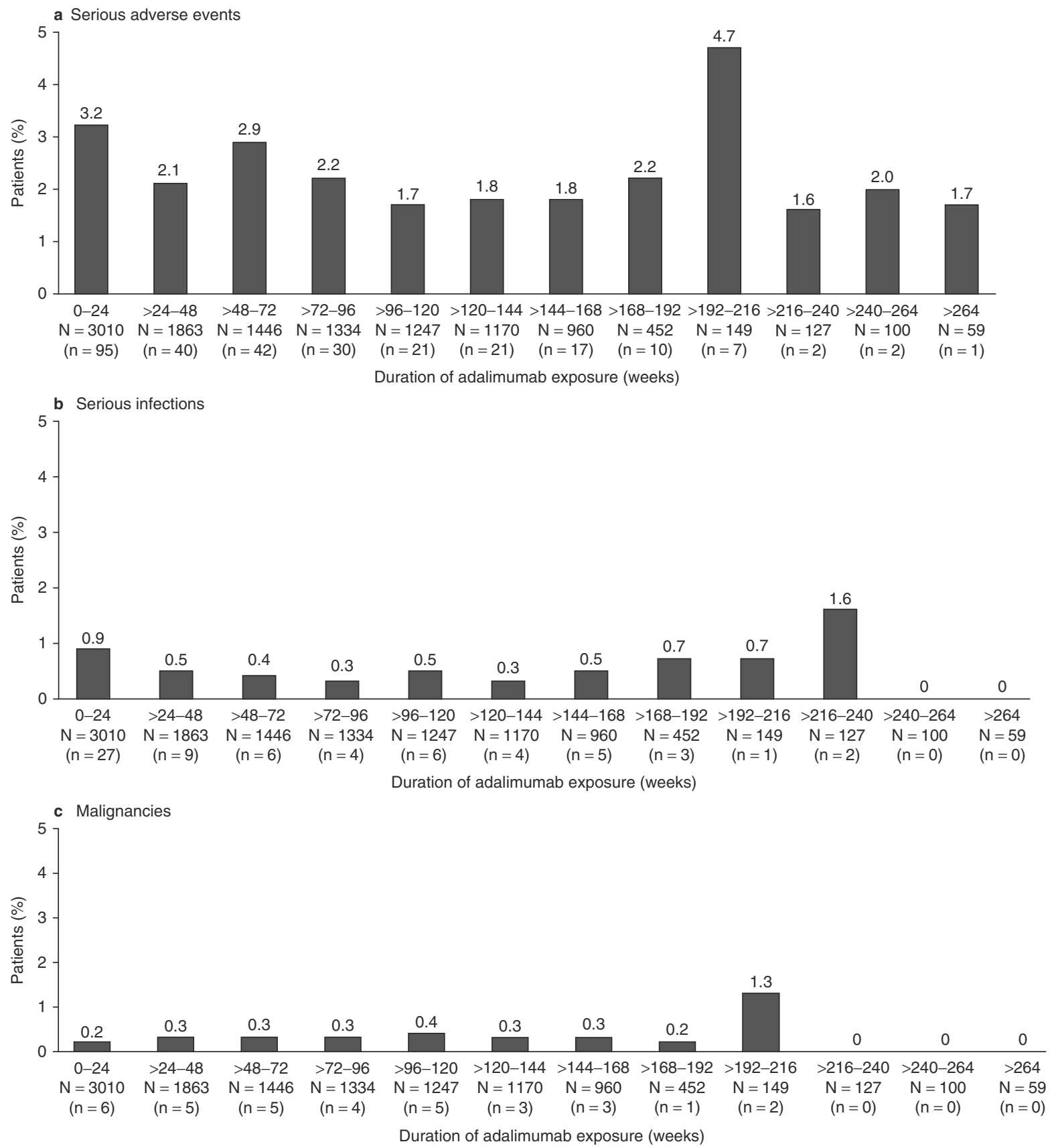

Fig. 3. Incidence rates of serious adverse events (a), serious infections (b), and malignancies (c) with increasing adalimumab exposure as of November 2009 for the All Adalimumab Treatment Population (AAT Population) [ $\mathrm{N}=3010]$. Rates of these adverse events were generally low and stable with increased exposure to adalimumab. N indicates the number of patients whose duration of exposure to adalimumab, as of 6 November 2008 , exceeded the minimum time of exposure for an interval. Patients whose duration of exposure exceeded the minimum number of weeks for more than one of the intervals were counted in ' $\mathrm{N}$ ' for each of those intervals. $\mathrm{n}$ indicates the number of patients who experienced at least one adverse event during an exposure interval. The percentage of the patients who experienced one or more adverse events during an exposure interval is shown above each bar. 

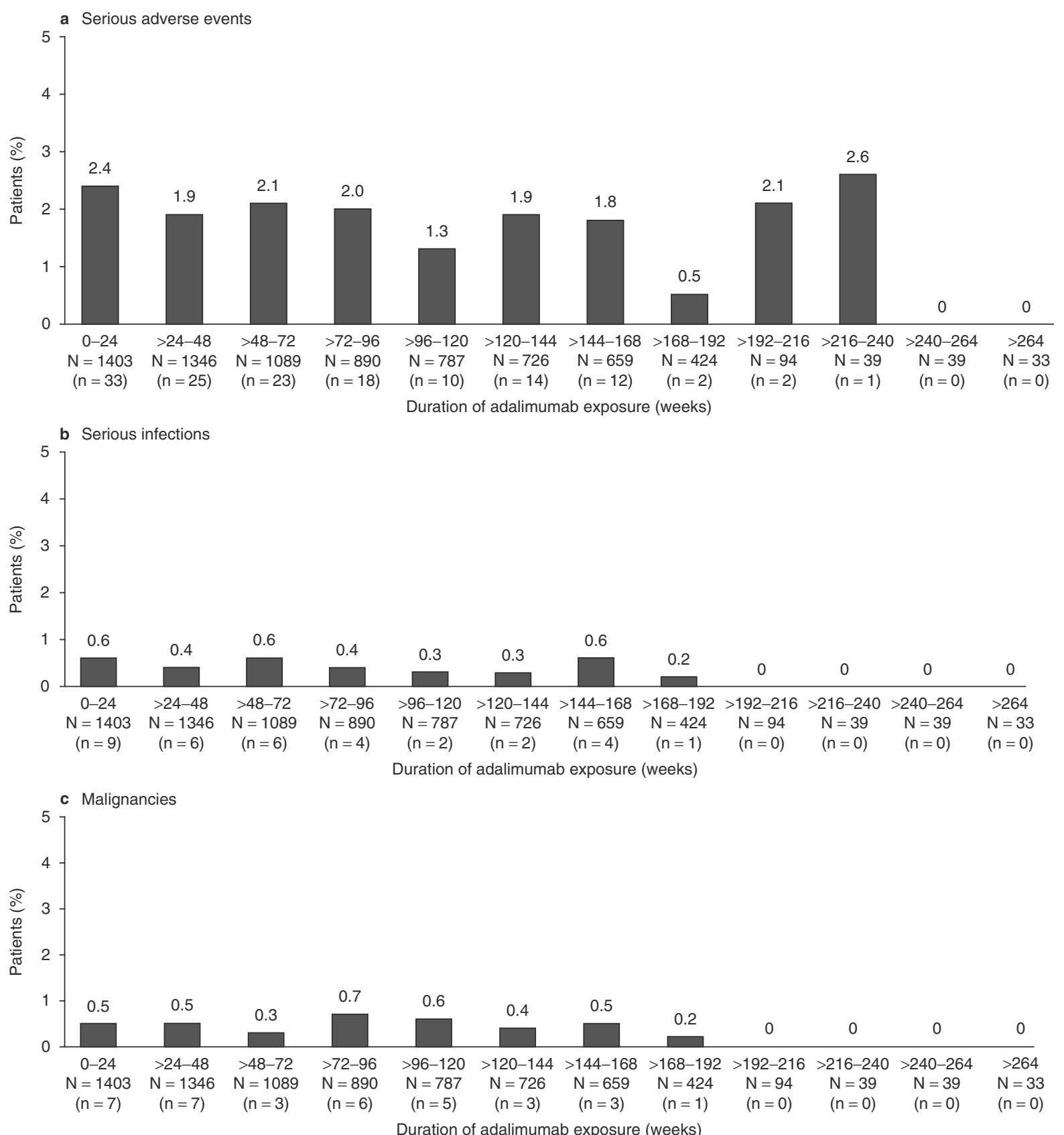

Fig. 4. Incidence rates of serious adverse events (a), serious infections (b), and malignancies (c) with increasing adalimumab exposure for the Every Other Week Population (EOW Population) [N=1403]. N indicates the number of patients whose duration of exposure to adalimumab, as of 14 April 2010 , exceeded the minimum time of exposure for an interval. Patients whose duration of exposure exceeded the minimum number of weeks for more than one of the intervals were counted in ' $\mathrm{N}$ ' for each of those intervals. $\mathrm{n}$ indicates the number of patients who experienced at least one adverse event during an exposure interval. The percentage of the patients who experienced one or more adverse events during an exposure interval is shown above each bar.

adalimumab exposure in the clinical trials program. The absolute difference in risk between the two datasets for a patient was $0.33 \%$.

As of November 2009, eight deaths were reported across all adalimumab clinical trials in psoriasis, resulting in a stand- ardized mortality ratio of $0.31(95 \%$ CI $0.13,0.62)$. This value is less than what has been reported for the general population in some databases. ${ }^{[23]}$ Most of the fatal adverse events were associated with cardiovascular disease. In this regard, multiple studies have reported an increased risk for cardiovascular dis- 
Table V. Deaths reported as of 6 November 2009 in the adalimumab psoriasis clinical trials program

\begin{tabular}{|c|c|c|c|c|c|c|}
\hline Age $(y)$ & Race $^{a}$ & Sex & Adverse event & Relevant history & Adalimumab dosing & $\begin{array}{l}\text { Adalimumab } \\
\text { exposure at onset (d) }\end{array}$ \\
\hline 46 & W & M & $\begin{array}{l}\text { Cerebrovascular } \\
\text { accident NOS }\end{array}$ & $\begin{array}{l}\text { Migraine headache, hypertension, } \\
\text { obesity, and long-term tobacco use }\end{array}$ & 40 mg weekly & 203 \\
\hline 50 & W & M & Completed suicide & Depression & $40 \mathrm{mg}$ eow & 435 \\
\hline 70 & W & M & Myocardial infarction & $\begin{array}{l}\text { Hypertension, hypercholesterolemia, } \\
\text { and morbid obesity }\end{array}$ & $\begin{array}{l}40 \text { mg eow (406 d); } \\
40 \text { mg weekly (170 d) }\end{array}$ & 576 \\
\hline 52 & W & M & Myocardial infarction & $\begin{array}{l}\text { Hyperlipidemia, hypertension, } \\
\text { diabetes mellitus, rheumatoid arthritis, } \\
\text { and long-term tobacco use }\end{array}$ & $40 \mathrm{mg}$ eow & 96 \\
\hline 50 & W & M & Coronary artery disease & $\begin{array}{l}\text { Long-term tobacco use and } \\
\text { myocardial infarction }\end{array}$ & $40 \mathrm{mg}$ eow & 1249 \\
\hline 78 & W & M & $\begin{array}{l}\text { Death was reported by } \\
\text { the investigator as due } \\
\text { to two fatal adverse } \\
\text { events: cerebrovascular } \\
\text { accident and coronary } \\
\text { artery disease }\end{array}$ & $\begin{array}{l}\text { Hypercholesterolemia, } \\
\text { hypertriglyceridemia, atrial fibrillation, } \\
\text { coronary artery disease, } \\
\text { hypertension, and myocardial } \\
\text { infarction }\end{array}$ & $\begin{array}{l}\text { Placebo ( } 112 \mathrm{~d}) \\
40 \mathrm{mg} \text { eow }\end{array}$ & 1140 \\
\hline 65 & W & M & Aortic aneurysm & Previous aortic aneurysm surgery & $\begin{array}{l}40 \text { mg weekly ( } 84 \mathrm{~d}) ; \\
\text { placebo ( } 84 \text { days); } \\
40 \text { mg eow ( } 1553 \text { days) }\end{array}$ & 1707 \\
\hline 42 & $\begin{array}{l}\text { American } \\
\text { Indian/Alaskan } \\
\text { Native }\end{array}$ & $\mathrm{F}$ & Unknown cause & Heavy alcohol use; one prior seizure & $40 \mathrm{mg}$ eow & 71 \\
\hline
\end{tabular}

a Race shown per patient selection on study form.

eow = every other week; $\mathbf{F}=$ female; $\mathbf{M}=$ male; $\mathbf{N O S}=$ not otherwise specified; $\mathbf{W}=$ White.

ease, including death due to cardiovascular disease, for patients with severe psoriasis. ${ }^{[21,22,24]}$ Using data from the UK General Practice Research Database, Abuabara and colleagues ${ }^{[23]}$ recently compared the risk of all causes of mortality in psoriasis patients with a history of systemic therapy, which the authors defined as severe psoriasis, with patients without a psoriasis diagnosis. A statistically significant increased risk of death in psoriasis patients was found to be due to increased incidence rates of cardiovascular disease, malignancies, chronic lower respiratory disease, diabetes mellitus, infection, kidney disease, and other 'unknown missing' causes. The absolute (6.19 deaths/100 PYs) and excess ( 0.35 deaths/100 PYs) risk of death was greatest for cardiovascular disease. In adalimumab clinical trials, $>40 \%$ of patients had a BMI $\geq 30$, elevated systolic or

Table VI. Tuberculosis (TB) cases reported as of 6 November 2009 in the adalimumab psoriasis clinical trials program

\begin{tabular}{|c|c|c|c|c|c|c|}
\hline Age $(y)$ & Race $^{a}$ & Sex & Adverse event & Screening results & Adalimumab dosing (mg eow) & Adalimumab exposure at onset (d) \\
\hline 40 & A & $\mathrm{M}$ & $\mathrm{TB}^{\mathrm{b}}$ & PPD-positive; normal chest radiograph & 40 & 139 \\
\hline 22 & W & $\mathrm{F}$ & Disseminated $\mathrm{TB}^{\mathrm{b}}$ & PPD-positive; normal chest radiograph & 40 & 138 \\
\hline 57 & $A$ & M & $\mathrm{TB}^{\mathrm{b}}$ & PPD-positive; normal chest radiograph & 40 & 167 (61 d post-last dose) \\
\hline 34 & A & M & Pulmonary TB & PPD-negative; normal chest radiograph & 40 & 65 \\
\hline 38 & $\mathrm{~B}$ & M & Pulmonary TB & PPD-negative; normal chest radiograph & 40 & 58 \\
\hline 67 & A & M & Pulmonary TB & PPD-negative; normal chest radiograph & 40 & 708 \\
\hline 36 & A & $M$ & TB & PPD-negative; normal chest radiograph & 40 & 793 \\
\hline
\end{tabular}

a Race shown per patient selection on study form.

b Prophylaxis compliance issues were noted in the medical records of all three cases of TB reactivation in PPD-positive patients.

$\mathbf{A}=$ Asian; $\mathbf{B}=$ Black; eow $=$ every other week; $\mathbf{F}=$ female; $\mathbf{M}=$ male; $\mathbf{P P D}=$ purified protein derivative; $\mathbf{W}=\mathbf{W}$ hite. 
Table VII. Malignant melanoma cases reported as of 6 November 2009 in the adalimumab psoriasis clinical trials program

\begin{tabular}{|c|c|c|c|c|c|c|}
\hline Age (y) & Race $^{a}$ & Sex & Adverse event & Relevant history & $\begin{array}{l}\text { Adalimumab } \\
\text { dosing }\end{array}$ & $\begin{array}{l}\text { Adalimumab } \\
\text { exposure at onset (d) }\end{array}$ \\
\hline 55 & W & M & $\begin{array}{l}\text { "Superficial spreading malignant } \\
\text { melanoma;"' left pre-auricular darkened patch } \\
\text { (Breslow } 0.51 \mathrm{~mm}, \text { Clark level II) }^{\mathrm{b}}\end{array}$ & $\begin{array}{l}\text { Current smoker ( } 1 \text { pack/day; } 30 \mathrm{y}) \\
\text { with no history of UVA or PUVA } \\
\text { phototherapy reported }\end{array}$ & $40 \mathrm{mg}$ eow & 198 \\
\hline 40 & W & M & Malignant melanoma in situ & $\begin{array}{l}\text { No history of UVA or PUVA } \\
\text { phototherapy reported }\end{array}$ & $40 \mathrm{mg}$ eow & 29 \\
\hline 43 & W & $\mathrm{F}$ & $\begin{array}{l}\text { Malignant melanoma site/stage unspecified } \\
\text { (Breslow } 0.51 \mathrm{~mm} \text {, Clark level III); } \\
\text { "lesion was inside a psoriasis plaque and } \\
\text { became noticeable only after clinical } \\
\text { improvement of psoriasis" }\end{array}$ & $\begin{array}{l}\text { No history of UVA or PUVA } \\
\text { phototherapy reported }\end{array}$ & $40 \mathrm{mg}$ eow & 113 \\
\hline 40 & W & $\mathrm{F}$ & $\begin{array}{l}\text { Melanoma site/stage unspecified; "invasive } \\
\text { to } 0.8 \mathrm{~mm} \text {," Clark level III-IV; no metastases } \\
\text { found; "lesion was of uncertain duration } \\
\text { and located in a tattoo" }\end{array}$ & $\begin{array}{l}\text { Remote history of UVA exposure } \\
\text { (tanning bed) }\end{array}$ & 40 mg weekly & 218 \\
\hline 50 & W & M & $\begin{array}{l}\text { Malignant melanoma in situ; (no evidence } \\
\text { of invasion, Clark level I) }\end{array}$ & $\begin{array}{l}\text { No history of UVA or PUVA } \\
\text { phototherapy reported; biopsy report } \\
\text { noted severe actinic damage }\end{array}$ & $\begin{array}{l}40 \mathrm{mg} \text { eow } \\
(286 \mathrm{~d}) ; \\
40 \mathrm{mg} \text { weekly } \\
(339 \mathrm{~d}) ; \\
40 \mathrm{mg} \text { eow }(43 \mathrm{~d})\end{array}$ & 668 \\
\hline 37 & W & M & $\begin{array}{l}\text { Superficial spreading melanoma stage } \\
\text { unspecified; event diagnosis: superficial } \\
\text { melanoma (Breslow } 0.39 \mathrm{~mm} \text {, Clark level II) }\end{array}$ & $\begin{array}{l}\text { No history of UVA or PUVA } \\
\text { phototherapy reported }\end{array}$ & $\begin{array}{l}40 \mathrm{mg} \text { eow } \\
(449 \mathrm{~d}) ; 40 \mathrm{mg} \\
\text { weekly }(82 \mathrm{~d})\end{array}$ & 531 \\
\hline 45 & W & $\mathrm{F}$ & $\begin{array}{l}\text { Malignant melanoma; "papule slightly } \\
\text { eroded left leg" }\end{array}$ & $\begin{array}{l}\text { No history of UVA or PUVA } \\
\text { phototherapy reported }\end{array}$ & $\begin{array}{l}40 \mathrm{mg} \text { eow } \\
(212 \mathrm{~d}) ; 40 \mathrm{mg} \\
\text { weekly } \\
(262 \mathrm{~d})\end{array}$ & 474 \\
\hline 60 & W & M & Malignant melanoma in situ ${ }^{d}$ & $\begin{array}{l}\text { Smoker (>10y); bilateral cataracts; } \\
\text { prior sun exposure; basal cell } \\
\text { carcinoma }\end{array}$ & $40 \mathrm{mg}$ eow & 1485 \\
\hline 56 & W & $\mathrm{F}$ & $\begin{array}{l}\text { Malignant melanoma; "superficially } \\
\text { spreading malignant melanoma;" (Clark } \\
\text { level III, pT1a); no evidence of metastases } \\
\text { (follow-up CT scan) }^{\mathrm{e}}\end{array}$ & $\begin{array}{l}\text { Extensive UVB and sun exposure; } \\
\text { long-term methotrexate use (>12y) }\end{array}$ & $\begin{array}{l}40 \mathrm{mg} \text { eow (plus } \\
\text { topical therapy) }\end{array}$ & 50 \\
\hline \multicolumn{7}{|c|}{ a Race shown per patient selection on study form. } \\
\hline \multicolumn{7}{|c|}{ b Resolved on day 261 after wide excision of the remaining lesion with free margins. } \\
\hline \multicolumn{7}{|c|}{ c Event considered resolved immediately following excision. } \\
\hline \multicolumn{7}{|c|}{ d Study drug was not interrupted; event was considered resolved following excision. } \\
\hline e Follc & I-up CT & day 1 & showed no evidence of metastases. & & & \\
\hline
\end{tabular}

diastolic BP, or elevated triglycerides, which is consistent with a population at increased risk of cardiovascular disease.

Across all trials of adalimumab in psoriasis, rates of coronary artery disease, myocardial infarction, congestive heart failure, and MACE were stable with increasing adalimumab exposure.

There were slightly greater rates of most adverse events, including serious adverse events, serious infections, and malig- nancies, in the 2009 versus the 2008 AAT Population. This apparent increase may be attributable, at least in part, to the large increase in the numbers of patients from brief trials with relatively little increase in adalimumab exposure between 2008 and 2009. Between 2007 and 2008, patient numbers increased by $20.8 \%$ (378 patients) and adalimumab exposure increased by $79.5 \%$ (1927.2 PYs). In contrast, between 2008 and 2009, 
patient numbers increased by $37.0 \%$ ( 813 patients), but adalimumab exposure increased by only $11.3 \%$ (492.8 PYs). Of note, the incidence rates of serious adverse events and serious infections were greater for patients with $\leq 24$ weeks of drug exposure as compared with almost all other 24-week intervals in both the $2008^{[25]}$ and 2009 datasets. $17.2 \%$ and $97.3 \%$ of patients whose data were first collected for the November 2008 and 2009 AAT Population datasets, respectively, had $\leq 24$ weeks of adalimumab exposure.

In the EOW Population, increased mean adalimumab exposure was consistently associated with decreased incidence rates of common adverse events over time. For adverse events of interest, less consistency was observed, i.e. an increase in the rate of serious adverse events, but a decrease in the rate of serious infectious adverse events was observed, with little or no change in most other specific adverse events of interest. Consistent with the results seen in the AAT Population, the analysis of incidence with serial 24-week intervals of exposure showed no evidence of cumulative toxicity for the EOW Population.

Taken together, the substantial increase in the proportion of patients with $\leq 24$ weeks of adalimumab exposure between 2008 and 2009 may at least partially explain the slightly greater adverse event incidence rates observed for the 2009 AAT Population.

Rates of serious infections remained stable despite increased adalimumab exposure. The most commonly reported serious infections were cellulitis, pneumonia, and abscess of the limb. There were no deaths due to serious infections in this analysis of all psoriasis clinical trials, and only single events of most types of serious infections were observed. None of the opportunistic infections that occurred in the psoriasis clinical trial program was classified as serious.

There have been conflicting reports regarding an increased risk of latent TB reactivation with the use of TNF $\alpha$ antagonists. ${ }^{[26]}$ Across all adalimumab trials in psoriasis, there were seven reported cases of TB. The overall TB incidence rate was 0.14/100 PYs. The equivalent incidence rate and risk for latent TB reactivation was $0.06 / 100 \mathrm{PYs}$, or approximately 6 in 10000 for one patient during 1 year of uninterrupted treatment. Of note, all three cases of latent TB reactivation were associated with compliance issues.

Compared with the expected number of malignancies in the US general population, the observed rate of malignancies (excluding NMSC) in the current analysis was slightly lower. For the November 2009 AAT Population, the expected number of malignancies was 32.2 (SEER database). Of the 36 events of malignancies (including lymphoma, but excluding NMSC) observed across all adalimumab trials in psoriasis, 29 malignancies met the NCI criteria for the SIR analysis, resulting in an SIR $(95 \%$ CI) of $0.90(0.60-1.29)$. For all studies combined, there was no evidence of an excess of diagnosed cancers in psoriasis studies compared with an age- and sex-matched population. For the November 2009 AAT Population, the SIR (95\% CI) for NMSC for patients receiving adalimumab in all psoriasis trials was $1.51(1.04,2.11)$ compared with the NCI survey. There were nine malignant melanomas and one lymphoma across all trials of adalimumab in moderate to severe psoriasis. Psoriasis patients have an increased risk of NMSC, and these results suggest that there is a small but significant increase in NMSC with adalimumab treatment as compared with the risk observed in the NCI comparator database. These results differed from those obtained from comparisons with databases in Arizona or Minnesota. The lack of an appropriately matched, comparator population, such as might be available with registry data, precludes the possibility of forming strong conclusions based on this observation. Of note, in the patient with lymphoma, evidence of malignancy was present at the time of study enrollment.

There were several important limitations to these analyses. There were fundamental differences between the AAT and EOW Populations. For example, data from all AAT Population patients were not represented in the 2007 and 2008 datasets. In this regard, the three AAT Population datasets represent a 'snapshot' of the safety information for all patients at the time of data collection. This was in contrast to the EOW Population, from which longitudinal data were available from the same 1403 patients in both the 2007 and 2010 EOW Population datasets. Also, the diversity of prior and concomitant treatments, treatment regimens, geographic locations, and other features of the trials contributing to the AAT Population was greater than is often reported for individual trials, or even integrated analyses of smaller numbers of trials, such as the EOW Population, but not as diverse as might commonly be seen in community practice. For these reasons, caution must be exercised when forming conclusions based on comparisons of the results from the AAT and EOW Populations. For similar reasons, comparisons between rates of adverse events in clinical trial populations and those in population databases may be of limited value. A substantial percentage of patients in the general population would be excluded from participation in psoriasis clinical trials. Thus, simple matching of baseline demographics and clinical characteristics alone between clinical trials and population databases in itself is not adequate to ensure that all clinically important variables have been addressed. These considerations apply to SIR and standardized 
mortality ratio results obtained as part of the current analyses, and underscore the need for data from large psoriasis registries.

\section{Conclusions}

Taken together, these data underscore the safety of adalimumab use in a moderate to severe psoriasis population, and the results are consistent with a favorable benefit-risk profile for adalimumab, and are similar to those of other TNF antagonists. ${ }^{[27]}$ This long-term, cumulative analysis of $>4800$ patient years of adalimumab exposure in psoriatic patients provides the most comprehensive overview extant of adalimumab safety data in this patient population.

\section{Acknowledgments}

Medical writing support was provided in the development and revision of this manuscript by Amy Gamelli, PhD, of Abbott Laboratories. The authors would like to thank Yuzhen Wang of Abbott Laboratories for statistical support.

Abbott Laboratories funded this study and participated in the study design, data collection, data management, data analysis, and preparation of the manuscript. All authors had full access to the data and were involved in the analysis of data, development and revision of the manuscript, and the decision to submit the manuscript for publication.

Drs Leonardi, Papp, Strober, Reich, Asahina, and Tyring each report having served as an investigator, speaker, consultant, and/or advisory board member for, and received grants, honorarium, and/or fellowship support from Abbott Laboratories. Dr Rozzo, Ms Gu, and Mr Beason are employees of Abbott Laboratories and own Abbott Laboratories stock and/or stock options.

Dr Leonardi reports having been an investigator, consultant, speaker, and advisory board member for Amgen; an investigator, consultant, and advisory board member for Centocor; an investigator and consultant for Pfizer; a speaker for Genentch and Warner Chilcott; an investigator for Allergan, Astellas, Alza, Altana, Celgene, Bristol Myers, CombinatoRx, Eli Lilly, Ferndale, Fujisawa, Galderma, Genentech, GlaxoSmithKline, Incyte, 3M Pharmaceuticals, Novo Nordisk, Protein Design Labs, Perrigo Israel Pharmaceutical, Schering Plough, Serono, Symbio, Medicis, RTL, Novartis, Vitae, Wyeth, Stiefel, Sirtris, Vascular Biogenics, and Maruho; and a consultant for Eli Lilly and Genentech.

Dr Papp reports having been an investigator, consultant, speaker, and advisory board member for Amgen, Astellas, Celgene, Centocor, Janssen, Johnson \& Johnson, Galderma, Merck, Novartis, and Pfizer; an investigator, consultant and speaker for Stiefel; an investigator, advisory board member, and consultant for UCB; an investigator and consultant for Eli Lilly and GlaxoSmithKline; an investigator and advisory board member for Graceway; and a consultant for Genentech.

Dr Strober reports having been an investigator, consultant, and advisory board member for Amgen; an investigator, consultant, speaker, and advisory board member for Centocor; a consultant and advisory board member for Celgene, Pfizer, Leo Pharma, and Novartis; and a consultant for Maruho. Dr Strober is currently employed at the Department of Dermatology, University of Connecticut School of Medicine, Farmington, CT, USA.
Dr Reich reports having been a consultant, speaker, and advisory board member for Biogen Idec, Celgene, Centocor, Galderma, Janssen-Cilag, Leo Pharma, MSD, and Novartis; a consultant and speaker for Medac; and a member of the data safety monitoring board for Pfizer. Dr Asahina reports having been an investigator, consultant, and speaker for Eisai and Mitsubishi Tanabe Pharma. Dr Tyring reports no other conflicts of interest.

\section{References}

1. Greaves MW, Weinstein GD. Treatment of psoriasis. New Engl J Med 1995; 332: $581-8$

2. Thaci D. Long-term data in the treatment of psoriasis. Br J Dermatol 2008; 159 Suppl. 2: 18-24

3. Winterfield LS, Menter A, Gordon K, et al. Psoriasis treatment: current and emerging directed therapies. Ann Rheum Dis 2005; 64 Suppl. 2: ii87-90; discussion iil-2

4. Menter A, Korman NJ, Elmets CA, et al. Guidelines of care for the management of psoriasis and psoriatic arthritis: section 4. Guidelines of care for the management and treatment of psoriasis with traditional systemic agents. J Am Acad Dermatol 2009; 61: 451-85

5. Burmester GR, Mease P, Dijkmans BA, et al. Adalimumab safety and mortality rates from global clinical trials of six immune-mediated inflammatory diseases. Ann Rheum Dis 2009; 68: 1863-9

6. Dommasch ED, Abuabara K, Shin DB, et al. The risk of infection and malignancy with tumor necrosis factor antagonists in adults with psoriatic disease: a systematic review and meta-analysis of randomized controlled trials. J Am Acad Dermatol 2011; 64 (6): 1035-50

7. Asahina A, Nakagawa H, Etoh T, et al. Adalimumab in Japanese patients with moderate to severe chronic plaque psoriasis: efficacy and safety results from a phase II/III randomized controlled study. J Dermatol 2010; 37: 299-310

8. Gordon KB, Blum RR, Papp KA, et al. Efficacy and safety of adalimumab treatment in patients with moderate to severe psoriasis: a double-blind, randomized clinical trial. Psoriasis Forum 2007; 13: 6-11

9. Gordon KB, Langley RG, Leonardi C, et al. Clinical response to adalimumab treatment in patients with moderate to severe psoriasis: double-blind, randomized controlled trial and open-label extension study. J Am Acad Dermatol 2006; 55: 598-606

10. Larian A, Emer JJ, Gordon K, et al. Efficacy and safety of a second adalimumab treatment cycle in psoriasis patients who relapsed after adalimumab discontinuation or dosage reduction: a double-blind, randomized, placebocontrolled trial. Psoriasis Forum. In press

11. Leonardi C, Langley RG, Papp K, et al. Adalimumab for treatment of moderate to severe chronic plaque psoriasis of the hands and feet: efficacy and safety results from REACH, a randomized, placebo-controlled, double-blind trial. Arch Dermatol 2011; 147: 429-36

12. Menter A, Tyring SK, Gordon K, et al. Adalimumab therapy for moderate to severe psoriasis: a randomized, controlled phase III trial. J Am Acad Dermatol 2008; 58: 106-15

13. Papp K, Crowley J, Ortonne JP, et al. Adalimumab for moderate to severe chronic plaque psoriasis: efficacy and safety of retreatment and disease recurrence following withdrawal from therapy. Br J Dermatol 2011; 164: 434-41

14. Saurat JH, Stingl G, Dubertret L, et al. Efficacy and safety results from the randomized controlled comparative study of adalimumab vs. methotrexate vs. placebo in patients with psoriasis (CHAMPION). Br J Dermatol 2008; 158: 558-66

15. Strober BE, Poulin Y, Kerdel FA, et al. Switching to adalimumab for psoriasis patients with a suboptimal response to etanercept, methotrexate, or phototherapy: efficacy and safety results from an open-label study. J Am Acad Dermatol 2011; 64: 671-81

16. Thaci D, Ortonne JP, Chimenti S, et al. A phase IIIb, multicentre, randomized, double-blind, vehicle-controlled study of the efficacy and safety of adalimumab with and without calcipotriol/betamethasone topical treatment in patients with moderate to severe psoriasis: the BELIEVE study. Br J Dermatol 2010; 163: 402-11 
17. World Health Organization. Mortality database [online]. Available from URL: http://www.who.int/whosis/database/mort/table1.cfm [Accessed $2010 \mathrm{Jul} 26]$

18. Dalrymple JM, Stamp LK, O'Donnell JL, et al. Pharmacokinetics of oral methotrexate in patients with rheumatoid arthritis. Arth Rheum 2008; 58: 3299-308

19. Demers AA, Nugent Z, Mihalcioiu C, et al. Trends of nonmelanoma skin cancer from 1960 through 2000 in a Canadian population. J Am Acad Dermatol 2005; 53: 320-8

20. Ridky TW. Nonmelanoma skin cancer. J Am Acad Dermatol 2007; 57: 484-501

21. Mehta NN, Azfar RS, Shin DB, et al. Patients with severe psoriasis are at increased risk of cardiovascular mortality: cohort study using the General Practice Research Database. Eur Heart J 2010; 31: 1000-6

22. Prodanovich S, Kirsner RS, Kravetz JD, et al. Association of psoriasis with coronary artery, cerebrovascular, and peripheral vascular diseases and mortality. Arch Dermatol 2009; 145: 700-3

23. Abuabara K, Azfar RS, Shin DB, et al. Cause-specific mortality in patients with severe psoriasis: a population-based cohort study in the U.K. Br J Dermatol 2010; 163: 586-92
24. Kimball AB, Guerin A, Latremouille-Viau D, et al. Coronary heart disease and stroke risk in patients with psoriasis: retrospective analysis. Am J Med 2010; 123: $350-7$

25. Leonardi C, Papp K, Asahina A, et al. Long-term safety of adalimumab for psoriasis: an analysis of all adalimumab exposure in all global clinical trials [abstract no. P3337]. Presented at the 68th Annual Meeting of the American Academy of Dermatology; 2010 Mar 5-9; Miami Beach (FL)

26. Gardam MA, Keystone EC, Menzies R, et al. Anti-tumour necrosis factor agents and tuberculosis risk: mechanisms of action and clinical management. Lancet Infect Dis 2003; 3: 148-55

27. Langley RG, Strober BE, Gu Y, et al. Benefit-risk assessment of tumour necrosis factor antagonists in the treatment of psoriasis. Br J Dermatol 2010; 162: $1349-58$

Correspondence: Dr Craig Leonardi, MD, Central Dermatology, 1034 S. Brentwood Blvd., St. Louis, MO 63117, USA.

E-mail: Craig.Leonardi@centralderm.com 